\title{
Prevalence and Risk Factors for the Development of GD in Some Eastern European Countries - Tendencies and Pharmacoeconomical Assessment for the Choice of Treatment
}

\author{
Valentina Petkova and Irina Nikolova \\ Medical University - Sofia, Faculty of Pharmacy \\ Bulgaria
}

\section{Introduction}

Diabetes is a metabolic disorder of fat, carbohydrate, and protein metabolism, characterized by resistance to the action of insulin, insufficient insulin secretion, or both. The two major classifications of diabetes mellitus (DM) are type 1 (insulin deficient) and type 2 (combined insulin resistance and relative deficiency in insulin secretion). They differ in clinical presentation, onset, etiology, and progression of disease. Two to five percent of pregnancies are complicated by diabetes, of which $90 \%$ are classified as gestational diabetes mellitus (GD) (Satman et al, 2002). GD is defined as glucose intolerance of variable severity which is first recognized during pregnancy, including individuals with previously undiagnosed diabetes as well as those in whom high glucose levels are provoked by pregnancy. This term should not be used for gravid women with previously diagnosed diabetes. GD has much in common with type 2 diabetes with similar genetic susceptibility, corresponding prevalence within a given population or ethnic group and similar risk factors. Both conditions can be considered as a mixture of insulin resistance (IR) and impaired insulin secretion. Indeed, GD is a predictor of future type 2 diabetes with a cumulative incidence of about $50 \%$ at 5 years. GD is also a predictor of the metabolic (resistance) syndrome and should probably be considered a cardiovascular risk factor for later life. Since its first description in the early 1950s, GD has been one of the most controversial syndromes in the field of diabetes. Pregnancy is a state of insulin resistance, characterized by raised circulating insulin concentrations as the maternal pancreas compensates for increased peripheral demands. If adequate compensation does not occur, GD develops. GD is a well-established risk factor for adverse infant health outcomes, including fetal macrosomia, birth trauma, neonatal hypoglycemia, and fetal death (Cetin et al., 1997). GD can predict that the children of women who have GD are at an increased risk for obesity, glucose intolerance, and diabetes during adulthood. There is still confusion about the type of diagnostic tests and diagnostic criteria for GD and a screening protocol (e.g. universal versus selective screening). Gestational diabetes complicates about $1-14 \%$ of all pregnancies, depending on the 
population and diagnostic tests that are used and ranges from mild degrees of hyperglycemia to insulin-dependent diabetes (Kim et al., 2007).

Gestational diabetes usually manifests in the latter half of pregnancy and is characterized by insulin levels that are insufficient to meet insulin demands.

\section{Risk factors for GD}

Risk factors for GD include obesity, family history of diabetes, age greater than 35 years of age, pre-diabetes detected before pregnancy, previous delivery of babies with birth weights greater than $4 \mathrm{~kg}$, sedentary lifestyles and some ethnical groups. The frequency of GD significantly increases with increasing number of risk factors. However, even a combination of risk factors does not reliably predict the likelihood of developing GD, missing up to $50 \%$ of cases in population based studies (Fraser \& Heller, 2007; Jang et al., 2003) estimates that if age $>30$ years, obesity (BMI > 27.3), family history of diabetes mellitus and glycosuria in the present pregnancy were included as risk factors, $56.5 \%$ of the total population had risk factors for GD. However, in the stated report, the prevalence of GD in Korea was $2.0 \%$, Thailand $-2.0 \%$ and U.S. Caucasians - 2.3\%. One large study of women with GD showed that an increased incidence of GD was associated with age over 35, thin or obese prepregnancy weight, previous stillbirth, previous spontaneous or induced abortion, previous low- or high-birth-weight infant and chronic hypertension (Johnstone, 1999; Hossein-Nezhad et al., 2007) found the age distribution and GD prevalence in 15-24 age group was $0.39 \%$ and $2.68 \%$ in the $35-45$ age group. The authors reported $33.33 \%$ of women with GD who had a positive family history of diabetes, compared with $10.3 \%$ of women in the normal group ( $\mathrm{p}<0.0001$ ). It is now well established that women with a family history of diabetes had three times higher odds for GD than women without a family history of diabetes. Perhaps other maternal health and lifestyle behaviors, such as levels of physical activity, or selective immigration, could play an important role (Scholl et al., 2002).

Obesity in pregnancy is increasing worldwide and is associated with increased risk of adverse outcomes for both mother and child. Maternal obesity is also accompanied by alterations in glucose metabolism and by perturbations in inflammatory markers, adipokines and vascular dysfunction. The link between obesity and IR has been recognised for many years and much of this association has been attributed to disturbances in adipocyte function and metabolism (Huda et al. 2010). Obesity has considerable effects on glucose metabolism in pregnancy with a loss of the reduction in fasting glucose in early pregnancy and significant enhancement of peripheral and hepatic IR. All women increase maternal fat stores in early pregnancy irrespective of prepregnancy adiposity to meet the feto-placental and maternal demands of late gestation and lactation. Normal pregnancy is associated with marked changes in glucose metabolism and IR to facilitate provision of fuel substrate for the fetus. In early pregnancy insulin secretion increases, while insulin sensitivity is unchanged, or even slightly improved. However, as pregnancy progresses, insulin-mediated glucose utilization worsens by $40-60 \%$ and insulin secretion increases several fold in order to maintain euglycaemia in the mother. The mechanisms for this increased risk are multifactorial and include effects on insulin signalling similar to those seen in obese non-pregnant women. Women of normal weight gain around $3.8 \mathrm{~kg}$ of fat during pregnancy although there is substantial variation. In women of normal weight the majority of fat is accumulated centrally in the subcutaneous compartment of the trunk and 
upper thigh. A large population-based Swedish study highlighted that an increase in BMI of $3 \mathrm{~kg} / \mathrm{m}^{2}$ between two consecutive pregnancies resulted in an increased risk of preeclampsia, GD, gestational hypertension, caesarean delivery, stillbirth and large for gestation age births even if a woman has a healthy BMI during pregnancy. (Villamor \& Cnattingius, 2006; Hossein-Nezhad et al, 2007) It reported 35\% prevalence of obesity (BMI of more than 27$)$ in women with GD, compared with $11.3 \%$ in normal women $(p<0.0001)$. Not only weight gained during pregnancy, but variations in body habitus or constitution, like high waist-hip ratios, short stature and higher body fat percentages at given BMI levels could contribute as a risk factors (Davis, 2008; Mensing et al., 2002; Scholl et al., 2002) Not surprisingly, obese women are 4 times more likely and severely obese women almost 9 times more likely to develop GD than lean women.

Pregnancy is also characterised by marked increases in plasma lipid concentrations as gestation advances. Plasma cholesterol and triglyceride concentrations rise by $25-50 \%$ and $200-400 \%$ respectively. The hyperlipidaemia of pregnancy is exaggerated further in obesity with higher serum triglyceride and very low density lipoprotein (LDL) cholesterol concentrations than those observed in lean women. This is seen together with lower high density lipoprotein (HDL) cholesterol, although LDL cholesterol and total cholesterol concentrations appear similar. This pattern of dyslipidaemia is similar to that of the metabolic syndrome in the non-pregnant population. Some of these pathways may well contribute to vascular and metabolic complications in obese pregnancy.

It is well established that people with high levels of visceral or intra-abdominal body fat are associated with increased risk for type 2 diabetes (Huxley et al., 2008) and impaired glucose tolerance even after adjustment for BMI. Recent evidence suggests that even modest fasting hyperglycaemia (between 4.2 and $5.6 \mathrm{mmol} / \mathrm{L}$ ), currently thought to be within normal limits, is linearly associated with adverse pregnancy outcomes including increased birth weight, caesarean delivery and neonatal hypoglycaemia (Huda et al, 2010). Women with a history of GD are metabolically vulnerable with insufficient $\beta$-cell reserve, and many are IR. Approximately $17-63 \%$ of women who are diagnosed with GD during pregnancy will develop it in future pregnancies, and are at a much greater risk of developing type 2 diabetes within 5-16 years. The risk varies with the magnitude of insulin resistance, for example, if the patient needed insulin in pregnancy or was noted to be obese, or developed GD before 24 weeks gestation, the risk is greater. There is also some evidence that further pregnancies accelerate the rate of decline of beta cell function in women with GD. Several studies have reported links between GD and the subsequent risk of type 2 diabetes. Recent meta-analysis reports that GD corresponds to a 7.4 fold increased risk for developing type 2 diabetes mellitus (Bellamy et al., 2009). In addition, numerous studies have reported an increased risk of GD in women who are overweight or obese compared with lean or normalweight women (Chatzi et al., 2009). GD identifies pregnancies at increased risk for adverse perinatal outcome. It also identifies mothers who are at increased risk of developing type 2 $\mathrm{DM}$ in the future and offers the possibility of interventions and early detection. Severity of glucose intolerance during pregnancy, insulin requirement during pregnancy, earlier diagnosis during pregnancy, family history of diabetes, recurrence of GD, increasing parity, maternal age, prepregnancy obesity, weight gain during and after pregnancy, presence of islet cell antibodies, and delivery of a macrosomic infant were reportedly the key risk factors for type $2 \mathrm{DM}$ in women with history of GD (Cho et al., 2006). One of the major determinants of the risk for the development of subsequent type 2 diabetes is ethnic origin. Ethnic group with high risk of developing diabetes are Hispanic, African, Native American, 
South or East Asian, Pacific Islands or Indigenous Australian. Women with previous GD have a higher prevalence of polycystic ovary syndrome (PCOS), which is a condition associated with IR. Similarly in a study of women with PCOS, GD developed in $20 \%$ of these women compared with only $9 \%$ of controls with an odds ratio of 1.9 . Women with PCOS often attend assisted fertility clinics and should be warned of the likelihood of developing GD if they become pregnant (Hyer \& Shehata, 2005; Metzger et al., 2010).

Maternal diabetes during pregnancy exposes the fetus to hyperglycemia resulting in increased fetal insulin levels, which are associated with increased birth weight, increased childhood and adult obesity, and increased risk of GD and type-2 diabetes during childbearing age (Kim et al., 2007).

Perinatal and maternal morbidity can be reduced by maintaining normoglycaemia in GD. To achieve good glycaemic control, women diagnosed with GD should monitor their blood glucose levels, exercise, and undergo nutrition counselling. Besides, medical treatment options should be incorporated in care plans. However, despite intensive treatment aiming at near normoglycemia, a surprisingly high risk of macrosomia and birth trauma has been reported among the neonates of mothers with GD. It would seem that the prevention of macrosomia should be the primary goal of GD management. Several studies suggest an increased rate of preeclampsia among women with GD, and a combination of maternal diabetes and pre-eclampsia is associated with poor perinatal outcome (Fan et al., 2006).

Untreated or poorly controlled gestational diabetes can hurt the baby. It can raise the risk of certain pregnancy complications, like high blood pressure in the mother and having a larger-than-normal baby (macrosomia), which may require a C-section. Studies have shown that in GD the frequency of having an overweight baby is almost double, the frequency of having preeclampsia is almost double, and the frequency of early delivery is 40 percent greater. It was proven that the proper identification and management of GD are associated with a decrease in mortality and morbidity in infants.

\section{Testing programs}

GD is associated with maternal (pre-eclampsia, hypertension, caesarean section) and foetal morbidity (macrosomia, birth trauma, hypoglycaemia, hyperbilirubinemia, hypocalcemia, respiratory distress syndrome). Moreover, GD uncovers a pre-existing metabolic abnormality that may precede the development of overt diabetes mellitus. Therefore, prompt diagnosis of GD is essential to reduce maternal and foetal morbidity and to allow subsequent attempt at preventing or delaying the onset of Type 2 diabetes.

Whether or not to screen for gestational diabetes is an issue of significant controversy. The ADA favors screening a woman who has risk factors for developing GD (e.g., severe obesity, personal history of GD or previous delivery of large-for-gestational age infant, glycosuria, PCOS or a strong family history of diabetes) at her first prenatal visit (American Diabetes Association [ADA], 2011). If test is abnormal, these individuals should be considered to have "overt" (not gestational) diabetes (ADA, 2010). If this screen is normal, testing should be repeated between weeks 24 and 28 of gestation. Pregnant women without these risk factors should undergo screening for GD between weeks 24 and 28 of gestation unless they are considered low risk. To be low risk, a woman must fulfill all the following criteria:

- age younger than 25 years,

- normal prepregnancy weight,

- no known diabetes in first-degree relatives, 
- not a member of an ethnic group with a high prevalence of GD,

- no history of abnormal glucose tolerance,

- no history of abnormal obstetric outcome.

Screening for GD utilizes the oral glucose challenge test. New ADA guidelines (ADA, 2011) and WHO guidelines stated to perform a $75 \mathrm{~g}$ oral glucose tolerance test (OGTT), with plasma glucose measurement fasting and at 1 and $2 \mathrm{~h}$ at 24-28 weeks. OGTT should be performed in the morning after an overnight fast of at least 10 hours and after at least 3 days of unrestricted diet and unlimited physical activity. The patient should remain seated and should not smoke during the test (Johnstone, 1999). Criteria for diagnosis of GD based on the OGTT are summarized in Table 1. Two or more values must be met or exceeded for a diagnosis of diabetes to be made.

\begin{tabular}{|l|l|}
\hline Fasting & $\geq 92 \mathrm{mg} / \mathrm{dL}(5.1 \mathrm{mmol} / \mathrm{L})$ \\
\hline 1 hour & $\geq 180 \mathrm{mg} / \mathrm{dL}(10.0 \mathrm{mmol} / \mathrm{L})$ \\
\hline 2 hours & $\geq 153 \mathrm{mg} / \mathrm{dL}(8.5 \mathrm{mmol} / \mathrm{L})$ \\
\hline
\end{tabular}

Table 1. Diagnosis of GD with a $75 \mathrm{~g}$ Glucose Load

Results of the Hyperglycemia and Adverse Pregnancy Outcomes (HAPO) study (Metzger et al., 2008), a large-scale ( 25,000 pregnant women) multinational epidemiologic study, demonstrated that risk of adverse maternal, fetal, and neonatal outcomes continuously increased as a function of maternal glycemia at 24-28 weeks, even within ranges previously considered normal for pregnancy. For most complications there was no threshold for risk. These results have led to careful reconsideration of the diagnostic criteria for GD. The International Association of Diabetes and Pregnancy Study Groups (IADPSG) recommended that all women not known to have prior diabetes undergo a $75 \mathrm{~g}$ OGTT at 2428 weeks of gestation. This probably will significantly increase the prevalence of GD, however there is mounting evidence that treating even mild GD reduces morbidity for both mother and baby (International Diabetes Federation [IDF], 2004). Women at high risk should be screened as soon as feasible. If the initial screening is negative they should undergo retesting at 24 to 28 weeks' gestation.

There are two principles (selective and universal) in testing which need to be distinguished. First, there is selective (or at-risk) clinical need for high risk patient (obesity, a family history of diabetes, a history of macrosomic stillbirth, etc.). Second, there is universal screening, for women not clinically identified as being at particular risk. Universal screening is more sensitive, while selective screening is less costly. Unfortunately, the use of risk factors for individuals is not very effective, can result in great inconsistencies, and is a source of uncertainty for obstetricians and midwives. Universal screening should, at the moment, depend on the local prevalence of type $2 \mathrm{DM}$ in the reproductive age group. Low-risk status requires no glucose testing, but this category is limited to those women meeting all of the following characteristics: age $<25$ years, normal weight before pregnancy, member of a population with a low prevalence of GD, no known diabetes in first-degree relatives, no history of abnormal glucose tolerance, no history of poor obstetric outcome. Where type 2 DM is common (for example many units in the USA, Saudi Arabia and the Gulf, and certain ethnic minorities), then a total population screen is justified (Forsbach et al., 1997). Universal screening is more sensitive and more practical when a family history of diabetes cannot be obtained reliably (Karcaaltincaba et al., 2009). The diagnosis of GD is associated with a risk of type 2 diabetes later in life, so it is unsurprising that the prevalence of GD in any 
population will be largely determined by those factors which predict such a risk (Fraser \& Heller, 2007)

Any woman diagnosed with GD should be screened for diabetes 6-12 weeks postpartum and should be followed up with subsequent screening for the development of diabetes or pre-diabetes. If the fasting plasma glucose (FPG) level is normal, then reassessment for DM should occur every 3 years. Family planning for subsequent pregnancies should be discussed, and monitoring for the development of symptoms of DM should be undertaken.

The goal of treatment is to reduce the risks of GD for mother and child by keeping blood glucose levels equal to those of pregnant women who don't have such a disease. The highest risk of complications is established when there is an increase of the initial level of preprandial blood sugar and when there is an increase of the postprandial glucose.

Scientific evidences show that controlling glucose levels can result in less serious fetal complications and increased maternal quality of life and insulin administered twice daily during the third trimester to mothers who have even a mild degree of hyperglycemia will reduce fetal size, and in particular fetal adiposity. The proper management GD includes special meal plans and scheduled physical activity and of course - daily blood glucose testing. The further steps may require insulin injections.

\section{Prevalence of GD}

GD is the most common metabolic disease of pregnancy. The prevalence of GD varies across the globe, as well as between racial and ethnic groups within the same country. In recent years there has been a reported increased trend in the prevalence of GD throughout the world, with huge health-care and economic costs (Bellamy et al., 2009). This is particularly the case in developed countries, such as the USA, the UK, Australia, China and New Zealand (Sinha et al., 2003; Ferrara et al., 2004; Joshy \& Simmons, 2006; Metzger \& Counstan, 1998; Fan et al., 2006; Carolan et al., 2010). The increased prevalence has been recently disputed, suggesting that more cases were identified through more aggressive universal screening. For example, Lopez-de-Andres et al. (Lopez-de-Andres et al., 2011) did not found increase in the prevalence of GD is Spain from 2001 to 2008. This partly coud be explained with the fact that with the selective approach, women at low risk for GD do not need to be screened and some cases could be missed. Several teams have tried to improve the sensitivity of selective screening by making the relevant protocols more inclusive. Through this 'tinkering', age has emerged as the most important risk factor for type 2 DM and, by extension, gestational diabetes. Accordingly, the lower threshold for screening has decreased from 30 years in earlier studies to 25 years in more recent ones.

Approximately $8 \%$ of all pregnancies with wide-ranging differences between countries (ranging from 1 to $16 \%$ depending on the population studied, screening protocols and diagnostic criteria used) are complicated by GD (Hossein-Nezhad et al., 2007). Furthermore, within the same country, the prevalence of GD is strongly influenced by race and culture. High prevalence rates have been reported in studies from Australia (Indian-born 15\%, Chinese 13.9\%) and the United States (Zuni Indians 14.3\%).

Increasing prevalence relates to a range of factors including advanced maternal age, obesity and migratory patterns (Ferrara et al., 2004; Joshy \& Simmons, 2006). Of particular interest here is the increase seen among specific ethnic groups (Joshy \& Simmons, 2006, Kim et al., 2007), which may relate to ethnic differences in maternal glucose concentrations (Scholl et al., 2002; Esakoff et al., 2005) and recent trends of obesity (Harris et al., 1997, Xiong et al., 
2001, Rosenberg et al., 2003; Ben-Haroush et al., 2004). Moreover, women of non-Caucasian ethnicity represent a considerable portion of childbearing populations in developed countries, and as rates of obesity and GD grow, there is a concordant increase in the risk of poorer pregnancy outcomes among these groups. GD is also associated with an increased maternal likelihood of developing diabetes type 2 in later life, and recent research postulates a link between GD, childhood obesity and later onset of diabetes in the offspring (Ferrara, 2007; Ricart et al., 2005; Carolan et al., 2010)

\section{USA}

In the USA more than 200,000 cases annually are complicated by GD (Bottalico, 2007). Only $1.5-2 \%$ of Midwestern white women develop GD, while up to $15 \%$ of Native American women from southwestern USA have been reported to develop GD. In the Hispanic, African-American and Asian populations of the USA, the incidence of GD is 5-8\%. Most women will return to normoglycemia postpartum, but $30 \%$ to $50 \%$ will develop type $2 \mathrm{DM}$ or glucose intolerance later in life. State-, city-, hospital-level GD prevalence estimates have consistently shown GD rates to be higher among Asian and Pacific Islander (API) mothers than among white, black, or Hispanic mothers (Lawrence et al., 2008; Chu et al., 2009) found that among $3,108,877$ births, US APIs had a substantially higher age-adjusted prevalence of GD $(6.3 \%)$ than whites $(3.8 \%)$, blacks $(3.5 \%)$, or Hispanics $(3.6 \%)$.

\section{Asia}

Oriental populations have different demographic characteristics (maternal age, height, BMI and frequency of obesity) to other ethnic populations and it is not clear to what extent the effects of age and obesity are interrelated. In Korea the life styles have changed rapidly to a westernized pattern characterized by sedentary occupations and consumption of refined food and a high-fat diet. Therefore it is reasonable to predict that the prevalence of GD in Korean women will increase as the prevalence of type 2 DM increases in the developing countries (Jang et al., 1995; 2003). The overall prevalence of GD in Korean women was estimated as $2.2 \%$. The patients with GD were older, shorter and had a higher prepregnancy weight, BMI and parity than normal controls. The prevalence of GD in women with a single risk factor was $1.3 \%$ higher than that in women without risk factors $(0.6 \%, p<0.05)$, but was lower than that in the population at large $(2.2 \%)$. However the prevalence increased to $33.3 \%$ in patients with 4 risk factors.

The DECODA study showed that India has a higher prevalence of diabetes than China or Japan (Ferrara, 2007) reported 3.8\% prevalence of GD in China (20512 women screened), however they could not determine if there is an increase in the incidence of GD, but state that it is possible that absolute rate of GD has increased in China, probably due to changes in the lifestyle, decreased physical activity and increased incidence of obesity. Shai et al. (Shai et al., 2006) found that Asian women had a higher risk of diabetes than White, Hispanic, or Black women. In addition, they found that weight gain increased risk of diabetes more for Asian than for other women. Hunsberger et al. (Hunsberger et al., 2010) found that, compared with women of other race/ethnicities, both high BMI and low BMI Asian women were at the greatest risk of having GD. Additionally, diabetes risk among Asians seems to increase with prolonged exposure to Western lifestyle. The Turkish Diabetes Epidemiology Study reported the highest prevalence of diabetes in southern Turkey compared with northern and central parts of Turkey (Satman et al., 2002). The approximately rate of GD in Turkey is $4 \%$ (Karcaaltincaba et al., 2009). 


\section{Europe}

Di Cianni et al. (Di Cianni et al., 2003) performed a retrospective study to evaluate the prevalence of GD by using both the selective and the universal screening approach and the presence of risk factors for GD in a cohort of Italian women. From June 1st, 1995 to December 31st, 2001, universal screening for GD was performed in 3950 women. In this analysis GD was significantly and independently associated to age, pre-pregnancy BMI, weight gain, height and family history of diabetes. The generated figures indicate that GCT was positive in $35.2 \%$ of cases, while the true prevalence of GD was $8.7 \%$. When the OGTT was performed in a random sample of women with negative GCT, about $6.5 \%$ were found to have GD. By extrapolation to the whole cohort, it was then calculated that the approximate true prevalence of GD in the general population can be as high as $12.3 \%$.Lopez-de-Andres et al. (Lopez-deAndres et al., 2011) reported the prevalence of GD is Spain from 2001 to 2008 to be $3.6 \%$. In Sweden, 7817 infants (of total number 892084) were born of mothers with GD between 1992 and 2004. This represents an incidence of GD of $0.9 \%$ in the studied population (Ahlsson et al., 2010). The number of adults with diabetes in the European region is expected to reach 55.2 million. And 33.40\% are from the eastern European region.

\section{Eastern Europe}

The prevalence of GD in Eastern Europe and especially in Bulgaria shows a very diverse prevalence. (IDF, 2011)

\begin{tabular}{|c|c|c|c|c|c|}
\hline Country & $\begin{array}{l}\text { percent with } \\
\text { diabetes } \\
\text { (20-79 years) } \\
2010\end{array}$ & $\begin{array}{l}\text { number of } \\
\text { people with } \\
\text { diabetes } \\
2010\end{array}$ & $\begin{array}{l}\text { percent with } \\
\text { diabetes } \\
(20-79 \text { years }) \\
2030\end{array}$ & population & $\begin{array}{l}\text { GDP nominal } \\
\text { total (USD) }\end{array}$ \\
\hline Albania & 4.8 & 102800 & 5.1 & 2986952 & 12.224 billion \\
\hline Belarus & 9.1 & 661100 & 9.0 & 9648533 & 52.887 billion \\
\hline $\begin{array}{ll}\text { 3. } & \text { Bosnia and } \\
\text { Herzegovina }\end{array}$ & 9.1 & 271100 & 8.6 & 3842566 & 16631 billion \\
\hline Bulgaria & 9.0 & 519500 & 7.8 & 7351234 & 44.843 billion \\
\hline Croatia & 9.2 & 315900 & 8.0 & 4486881 & 59917 billion \\
\hline 6. Estonia & 9.9 & 97900 & 9.0 & 1340021 & 19.123 billion \\
\hline 7. Greece & 8.8 & 754000 & 7.4 & 11305118 & 325088 billion \\
\hline 8. Latvia & 9.9 & 169700 & 9.0 & 2217969 & 23955 billion \\
\hline 9. Lithuania & 9.7 & 239800 & 9.0 & 3244000 & 35.152 billion \\
\hline 10. Macedonia & 8.0 & 119300 & 8.0 & 2052722 & 9470 billion \\
\hline 11. Moldova & 8.7 & 233500 & 9.0 & 3567500 & 5403 billlion \\
\hline 12. Montenegro & 8.4 & 35700 & 8.0 & 620000 & \\
\hline 13. Romania & 8.4 & 1351400 & 8.0 & 21959278 & 158393 billion \\
\hline 14. Russia & 9.0 & 9624900 & 9.0 & 142905200 & 1477 trillion \\
\hline 15. Serbia & 8.6 & 613400 & 8.0 & 9981929 & 43.6 billion \\
\hline 16. Ukraine & 9.6 & 3328400 & 9.0 & 49100000 & 37.6 billion \\
\hline
\end{tabular}

Table 2. The DM morbidity in Eastern European region. 
According to the data, provided by the Diabetes Atlas, Estonia, Latvia and Ukraine are those eastern European countries with highest percentage of diabetes for 2010. Albania is the country with lowest percentage. Totally 18438400 is the number of the patients with diabetes in these sixteen countries. The mean percentage with diabetes for 2010 is 8.76 . And the decrease for the next 20 years will be insignificant -8.24 . Of course all the eastern European countries are extremely diverse as the population and gross domestic product (GDP) are taken in mind. Russia is the richest, while Moldova, Macedonia and Albania are the poorest. The number of deaths attributable to diabetes (20-79 years) is 317955 . And there is no significant differentiation by sex 143810 - males and 174145 - females. A very interesting fact is that only five countries - Greece, Russia, Belarus, Ukraine and Romania have National Diabetes program according to a survey of International Diabetes Federation (IDF) member associations. Bulgaria for example is working in order to develop and implement a national diabetes program. The Bulgarian Diabetes Association (BDA) that is the only one national representative association for patients and diabetics in Bulgaria is working towards achieving this goal. It was created in 1990. On the initiative of the Group for parliamentary consensus to combat socially significant diseases in the 40th National Assembly of Bulgaria and under the auspices of the National Assembly on 2-3 February 2008 in Plovdiv, Bulgaria there was a consensus around three significant acts:

1. Restriction of diabetes in Bulgaria and particularly the preparation and implementation of diabetic register and national program to combat diabetes should be one of the priorities of all institutions in Bulgaria.

2. It is the creation of a working group of representatives of all stakeholders to draw up an action plan for prevention, early diagnosis and proper treatment of diabetes in Bulgaria. These documents must be submitted for consideration and adoption by the National Assembly during the autumn session of 2008.

3. After the program and action plan, responsible institutions is imperative to take all necessary actions to ensure adequate funding for their practical application in the country. So we can conclude that Bulgaria is working towards the development of a National program.

Of course not only the disease itself has to be assessed but also the complication that accelerates the mortality. Close to four million deaths in the 20-79 age group may be attributable to diabetes in 2010, accounting for $6.8 \%$ of global all-cause mortality in this age group. According to the literay sources - this number resembles the deaths in this age group from several infectious diseases. The highest number of deaths due to diabetes is expected to occur in countries with large populations as they have the largest numbers of people with diabetes like Russia.

Another very important aspect is the health expenditures per person with diabetes in 2010 . As it can be seen there are very big fluctuations in the Eastern European region. For example Greece spent 2742 USD, while Moldova - only 76 USD. In order to be precise in the conclusions it has to be analyzed the GDP in order to compare these expenditures. For Greece it is 325088 billion USD , while for Moldova - 5403 billlion. For Greece these mean health expenditures per person with diabetes are $0.0084 \%$ from the GDP of the country, while for Moldova $-0.014 \%$. Bulgaria spent $0.007 \%$ from the GDP of the country for treatment of a patient with diabetes. (IDF, 2011) 


\begin{tabular}{|l|c|}
\hline Country & $\begin{array}{l}\text { Mean health expenditure per person with diabetes } \\
\text { in 2010 (USD) }\end{array}$ \\
\hline Albania & 261 \\
\hline Belarus & 238 \\
\hline Bosnia and Herzegovina & 307 \\
\hline Bulgaria & 301 \\
\hline Croatia & 736 \\
\hline Estonia & 584 \\
\hline Greece & 2742 \\
\hline Latvia & 493 \\
\hline Lithuania & 521 \\
\hline Macedonia & 287 \\
\hline Moldova & 76 \\
\hline Montenegro & 14 \\
\hline Romania & 145 \\
\hline Russia & 261 \\
\hline Serbia & 238 \\
\hline Ukraine & 307 \\
\hline
\end{tabular}

Table 3. Mean health expenditures per person with DM in 2010 for the Eastern European region.

The statistics by country for gestational diabetes shows that apporximatelly 1 in 2014 or $0.05 \%$ or 135000 women get GD every year in the USA. The analysis of the data for the eastern European region are shown in Table 4.

\begin{tabular}{|l|c|c|}
\hline Country & $\begin{array}{l}\text { Extrapolated } \\
\text { Incidence }\end{array}$ & $\begin{array}{l}\text { Population estimated used } \\
\text { (US Census Bureau, International data } \\
\text { base 2004) }\end{array}$ \\
\hline Albania & 1759 & 3544808 \\
\hline Belarus & 5117 & 10310520 \\
\hline $\begin{array}{l}\text { Bosnia and } \\
\text { Herzegovina }\end{array}$ & 202 & 407608 \\
\hline Bulgaria & 3731 & 7517973 \\
\hline Croatia & 2231 & 4496869 \\
\hline Estonia & 665 & 1341664 \\
\hline Greece & 5284 & 10647529 \\
\hline Latvia & 1144 & 2306306 \\
\hline Lithuania & 1790 & 3607899 \\
\hline Macedonia & 1012 & 2040085 \\
\hline Romania & 11095 & 22355551 \\
\hline Russia & 71457 & 143974059 \\
\hline $\begin{array}{l}\text { Serbia and } \\
\text { Montenegro }\end{array}$ & 5373 & 10825900 \\
\hline Ukraine & 23690 & 47732079 \\
\hline
\end{tabular}

Table 4. Extrapolated incidence of GD (wrongdiagnosis.com, 2011) 
These statistics are calculated extrapolations of various prevalence or incidence rates against the populations of a particular country or region. The statistics used for prevalence/incidence of GD are typically based on US, UK, Canadian or Australian prevalence or incidence statistics, which are then extrapolated using only the population of a given country. The base is that $0.05 \%$ from the population (women) will get GD annually. The literary data shows that the frequency of development of GD varies from 2 to $4-5 \%$ from the pregnant women. Some authors even state that $9 \%$ from the pregnant women develop GD. In Bulgaria a pilot study shows that the frequency is even greater $-14 \%$, but till today there was not perform a systematic screening. Unfortunatelly in Bulgaria there is a tendency for doubling the GD morbidity, because of the obesity and because of the increase survival rate of girls born with weight above $4 \mathrm{~kg}$.

\section{St. Vincent declaration - Review and principles}

In 1989, in St. Vincent, Italy was signed the St. Vincent declaration, a joint initiative of the International Diabetes Federation European region and the WHO European regional office. It is a program for strategic action to reduce the human and economic burden of diabetes in Europe and has been adopted by most of the European governments. (IDF, 2004) The St. Vincent initiative has few target areas, which seek to improve the quality of life of people with diabetes and to promote education of patients so to prevent diabetes complications. Patient education is very important and a team approach, including physicians, pharmacists and nurses, is beneficial. Some of the main conclusions during the meeting were that "diabetes mellitus is a major and growing European health problem, a problem at all ages and in all countries. It currently threatens at least ten million European citizens. It is within the power of national governments and health departments to create conditions in which a major reduction in this heavy burden of disease and death can be achieved. Countries should give formal recognition to the diabetes problem and deploy resources for its solution. Plans for the prevention, identification and treatment of diabetes and particularly its complications should be formulated at local, national and European regional levels. General goals and five-year targets can be achieved by the organised activities of the medical services in active partnership with diabetic patients, their families, friends and workmates and organisations in:

- The management of their own diabetes and education for it.

- The planning, provision and quality audit of health care.

- National, regional and international organisations for disseminating information about health maintenance.

- $\quad$ Promoting and applying research. (IDF, 2004)

The St. Vincent's declaration outlined the following general goals for children and adults with diabetes:

- $\quad$ sustained improvement in health experience and a life experience approaching normal expectation in quality and quantity.

- $\quad$ prevention and cure of diabetes and its complications by intensifying research effort.

The five-year targets that are granted in the declaration are:

- elaboration, initiation and evaluation comprehensive programmes for the detection and control of diabetes and its complications with self-care and community support as major components. 
- $\quad$ steps for raising the awareness in the population and amongst health care professionals of the present opportunities and the future needs for the prevention of diabetes and its complications.

- organisation training and teaching programs in diabetes management and care for people of all ages with diabetes, for their families, friends and working associates and for the health care team.

- ensuring that care for children with diabetes is provided by individuals and teams specialised in the management of both diabetes and children, and that families with a diabetic child get the necessary social, economic and emotional support.

- reinforcement of the existing centres of excellence in diabetes care, education and research.

- $\quad$ promotion of independence, equity and self-sufficiency for all people with diabetes, i.e. children, adolescents, those in the working years of life and the elderly.

- $\quad$ attempts for reducing the hindrances to the fullest possible integration of the diabetic citizen into society.

- implementation of effective measures for the prevention of costly complications:

\begin{tabular}{|c|c|}
\hline & reduce new blindness due to diabetes by one third or more. \\
\hline b & $\begin{array}{l}\text { reduce the number of people entering end-stage diabetic renal failure by at least } \\
\text { one third. }\end{array}$ \\
\hline $\mathrm{C}$ & reduce by one half the rate of limb amputations for diabetic gangrene. \\
\hline $\mathrm{d}$ & $\begin{array}{l}\text { cut morbidity and mortality from coronary heart disease in the diabetic by } \\
\text { vigorous programmes of risk factor reduction. }\end{array}$ \\
\hline e & $\begin{array}{l}\text { achieve a pregnancy outcome in the diabetic woman that approximates that of } \\
\text { the non-diabetic woman. }\end{array}$ \\
\hline
\end{tabular}

- $\quad$ establishment of monitoring and control systems, using new information technology for quality assurance of diabetes health care revision and for laboratory and technical procedures in diabetes diagnosis, treatment and self-management.

- $\quad$ promotion and granting of collaboration of European and international programmes of diabetes research and development through national, regional and World Health Organisation agencies and in active partnership with diabetes patients' organisations.

- taking urgent action in the spirit of the WHO programme 'Health for All' to establish joint initiative between the WHO and the International Diabetes Federation (European region) to initiate, accelerate and facilitate the implementation of these recommendations." (IDF, 2004)

Since 1989 further implementation and evaluation meetings have been held in Budapest (1992), Athens (1995), Lisbon (1997) and Istanbul (1999), where representatives of ISPAD have helped to formulate recommendations on behalf of children and adolescents.

\section{Pharmacoeconomical assessment of GD drug treatment. The role of the pharmacist for GD management}

The standard treatment of GD is insulin treatment. The metabolic control target in the GD treatment is blood sugar before meal under $5.8 \mathrm{mmo} / 1$, postprandial blood sugar under 7.5 $\mathrm{mmo} / 1$ and hemoglobin $\mathrm{HbA}_{1-\mathrm{c}}$ under $6.5 \%$. The postprandial blood glucose is of critical 
importance for the neonatal end of the pregnancy. That is why it is very important to determine the cost and effectiveness of the drug treatment for women with GD. It can be achieved by studying the clinical effectiveness of the treatment with diet and diet + insulin for pregnant women with GD and determination of the ratio treatment cost/effectiveness. A prospective study of 50 women with gestational diabetes from Sofia, Bulgaria were studied from pharmacoeconomical point of view. They were divided into 2 groups: Group I $(n=30)$ pregnant women only on a diet and Group II $(n=20)$ - pregnant women treated by a diet and insulin. The following including criteria were applied: age above 18 years, one fetus pregnancy, insignificant additional disease without organ damages, without infectious diseases, without obesity and $\mathrm{HbA}_{1-c}$ under $7 \%$. The key excluding criteria are the availability of diabetes before pregnancy, or prior insulin therapy, treatment with oral hypoglycemic drugs before pregnancy, income of drugs that have influence on the carbohydrate tolerance, existing obstetrics complications till the demonstration of the gestation diabetes. The diet treatment was with diet No 9 according to M.I. Pevzner. The diet satisfies the recommendations for feeding. Human insulin, in intensified insulin regimen type- bazalprandial, including treatment with three doses rapid acting insulin and one or two doses intermediate acting insulin was applied. The total costs of the treatment of a patient, on a diet without complications in the peripartal period is 335.02 USD and is lower in comparison with the total cost of the treatment of a woman treated only with insulin that is 347.42 USD. $(p=0.04)$. The difference in the treatment cost is 12.40 USD. The total treatment cost of a pregnant woman, treated with diet with complications in the peripartal period is 363.94 USD and is also lower in comparison with the total cost of the treatment of a woman treated with insulin and with complications that is 398.90 USD $(p=0,03)$. (Todorova et al., 2007)

The cost-effectiveness coefficient is calculated based on the total direct medical costs, used for the reduction of the average 24-houred glucose under 5,8 $\mathrm{mmol} / 1$ as for higher precision the calculations are proceeded with the received difference in the level of the glycated hemoglobin after the treatment. (Todorova et al., 2007) The over calculated CCE for 100 women is CCE is 5141.17 USD

$\mathrm{CCE}=398.90-363.94 / 6,1-5,42=51.4117 \mathrm{USD}$

$51.4117 \times 100=5141.17$ USD

The so calculated coefficient reflects the costs for complications that is saved by the insulin treatment and that should occur after an ineffective diet treatment. The interpretation of this coefficient shows that the spent 12.40 USD for insulin treatment for every woman in fact saves 51.41 USD that should be spent for the treatment of unfavorable peripartal maternal complications. Through the application of a model of mathematical modeling the total final cost for one beneficially treated woman with GD is calculated. The calculations for the two therapeutical alternatives are performed by the use of the probabilities for occurrence of effective treatment for each of them.

The total costs of the treatment with diet is 351.69 USD

$(334.43 \times 0,4)+(363.2 \times 0,6)=351.69$ USD

The total cost of the treatment with insulin is 349.35 USD.

$(346.84 \times 0,95)+(398.2 \times 0,05)=349.35$ USD

The applied analytical model shows that on the base of the higher per cent successfully treated women, the spent final costs for successfully treated woman after the treatment with insulin are 388,13 USD $(349.32 / 0,9)$, and the final costs after the treatment with diet are 879.1 USD (351.64/0,4). (Todorova et al., 2007) 
349.34 USD

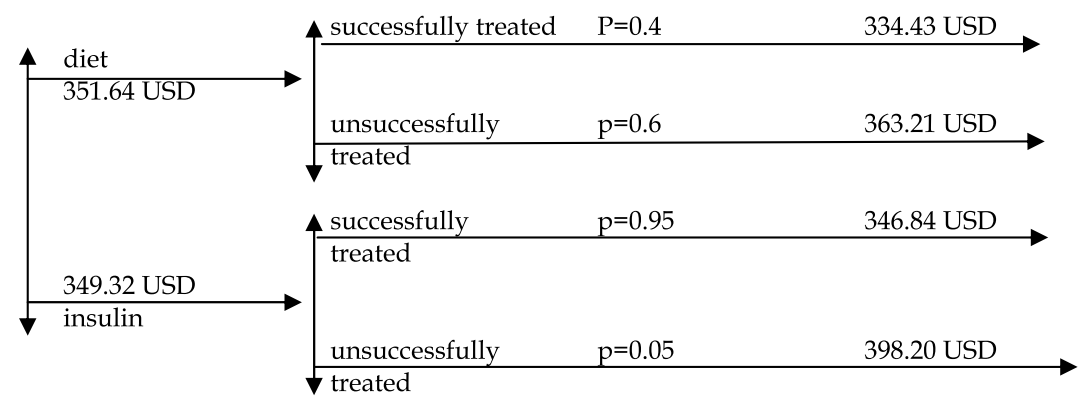

Table 5. "Three of decisions" of the alternatives for the treatment of GD.

There are four clinical paths, concerning diabetes that are included in the list of the Bulgarian Health Insurance fund. Unfortunatelly there is no clinical path concerning DM or the complications of this disease that decreases the accessibility towards proper management of this disease. And on this base it can be explained the prospective data about doubling the GD morbidity.

\begin{tabular}{|c|c|c|c|c|}
\hline $\begin{array}{l}\text { Clinical } \\
\text { path No }\end{array}$ & disease & $\begin{array}{l}\text { Hospital } \\
\text { stay }\end{array}$ & Drug treatment & $\begin{array}{l}\text { Prize } \\
(\text { USD)/daily }\end{array}$ \\
\hline 8 & Diabetes polineuropathia & 3 days & $\begin{array}{l}\text { carbamazepine - } 400- \\
800 \mathrm{mg} / \text { daily. } \\
\text { gabapentin - from } 3 \\
\text { times x } 300 \mathrm{mg} \text { till } 1500 \\
\text { mg daily; } \\
\text { pregabalin - up to } 2 \times \\
150 \mathrm{mg} ;\end{array}$ & $\begin{array}{l}0.23-0.46 \\
2.34-3.90 \\
3.92\end{array}$ \\
\hline 104 & $\begin{array}{l}\text { Decompensated DM for } \\
\text { patients above } 18 \text { years }\end{array}$ & 3 days & $\begin{array}{ll}\text { - } & \text { Insulin } \\
\text { - } & \text { Electrolities }\end{array}$ & 9.57 - once \\
\hline 105 & $\begin{array}{l}\text { Decompensated DM for } \\
\text { patients bellow } 18 \text { years }\end{array}$ & 3 days & $\begin{array}{ll}- & \text { Insulin } \\
\text { - } & \text { Electrolities }\end{array}$ & 9.57 - once \\
\hline 178 & $\begin{array}{l}\text { Surgical Intervention Of } \\
\text { Diabetic Foot without } \\
\text { vessel reconstruction }\end{array}$ & 3 days & & \\
\hline
\end{tabular}

Table 6. Clinical paths in Bulgaria, concerning diabetes.

Another aspect that is innovative in the Bulgarian pharmaceutical practice, concerning the management of GD is the role of the pharmacist as a health-care educator in order to be accomplished the St. Vincent declaration aims is demonstrated. Patient education is very important and a team approach, including physicians, pharmacists and nurses, is beneficial.(38). A study that included pregnant women attending antenatal clinic with GD January 2009 - December 2009 demonstrated the beneficial role of patients education. The following including criteria are used: age above 18 years, one-fetus pregnancy, GD, insignificant additional disease without organ damage, without infectious diseases. The 
study design is a pilot case-control study that includes 45 women with GD from city of Sofia, Bulgaria. The pregnant women were divided into two groups - Group I $(n=22)$, that were educated on the proper management of their disease and were on a diet and treated with insulin, and Group II $(n=23)$, that were not educated and on a diet, but treated with insulin on a regimen, prescribed by the physician. The assignment was based on the principle of random numbers through custom random number generator. The educational program continued 3 months. It was designed and adapted to the patients comfort, provided at the pharmacy they are attending. The course was presented to the 22 previously selected pregnant women with GD.

The educational course included the following teaching units:

- $\quad$ The essence of GD;

- The complication of improper disease management;

- Proper diet regimen (based on the Sample GD diet menu of the Endocrinology clinic of

Minneapolis) and also proper drug treatment as well as hypo-and hyperglycaemia and physical activity for both of the groups.

The first unit acquainted each of the women with the aim of the educational program, provided general concept about GD and about self-monitoring and emphasized on the active patient participation in the treatment. The personal information of each of the patients was collected, concerning the duration of the disease, the prescribed drug treatment if any, the frequency of the hypoglycaemic and hyperglycaemic incidents. At the end of the first unit, each of the patients was supplied with written materials on the essence of GD. The goal was to learn the seriousness of GD.

The main topic discussed during the second teaching unit was complication of improper management. The educator explained the complications of GD. The educator discussed with every woman the effects on the fetus.

The main topic discussed during the third teaching unit was proper diet regimen (based on the GD diet menu of the Endocrinology clinic of Minneapolis, USA). At the end of the session the patients were supplied with the Sample GD diet menu. Each of the patients was supplied with written materials on proper nourishing for diabetic patients and physical activity.

The educational materials used during the program included:

- a set of one-page written materials that illustrate the most important aspects of every educational lecture, provided to the patient after every session;

- questionnaire cards for distribution among the participants as a standardized procedure for assessment of their knowledge acquired in the previous educational units;

- individual food and activity record for the self-monitored data (food, total grams of carbs, comments and activities, insulin treatment);

In the beginning and at the end of the educational process a patient satisfaction questionnaire was applied (Diabetes Questionnaire (IMG)). During the 3-months education and its end, the observed behavioural parameters performed changes. The results from the twice-applied questionnaire assessing the quality of life of the patients in the beginning and in the end of the educational programme show that the five main indices have been improved with on the average of $5 \%$ for the both groups, but greater for those included in Group I (Table 7). The greater increase was observed in the positive changes in the mood $7,9 \%$ for Group I and 8,2\% for Group II , followed by number of days "being easy" with 6.9 $\%$ for Group I and with 6,2\% for Group II (6.7\%) and possibility to perform physical activities $5.8 \%$ for Group I and 5\% for Group II. It could be considered that the educational 
process affects both the physical and the psychological well-being and thus it is beneficial for the global patient's quality of life.

\begin{tabular}{|c|c|c|c|c|}
\hline \multirow{3}{*}{ Variable } & \multicolumn{4}{|c|}{ Time period } \\
\hline & \multicolumn{2}{|l|}{0} & \multicolumn{2}{|l|}{3 month } \\
\hline & Group I & Group II & Group I & Group II \\
\hline QL-positive changes in the mood & $10,8 \%$ & $9,9 \%$ & $18,7 \%$ & $18,1 \%$ \\
\hline QL-increase in days "being easy" & $18,4 \%$ & $17,9 \%$ & $25,3 \%$ & $24,1 \%$ \\
\hline QL- increase in social activity & $11,1 \%$ & $12,2 \%$ & $14 \%$ & $15,1 \%$ \\
\hline QL- increase in days being "rested" & $15 \%$ & $14,5 \%$ & $17,4 \%$ & $16,8 \%$ \\
\hline QL- increase in physical activity & $13,4 \%$ & $14,0 \%$ & $19,2 \%$ & $19,0 \%$ \\
\hline total & $68,70 \%$ & $68,50 \%$ & $94,60 \%$ & $93,10 \%$ \\
\hline mean & $13,74 \%$ & $13,70 \%$ & $18,92 \%$ & $18,62 \%$ \\
\hline
\end{tabular}

Data are \%. QL - "quality of life".

Table 7. Changes in the patients sample after the educational process

The advanced pharmacy practitioner in diabetes management is a relatively new approach. The role of the pharmacist in it, integrates drug management, patients' compliance assessment, blood glucose monitoring, skills training, prospective and retrospective drug utilization review, adverse drug reaction and toxicity screening and education of the patients.(Valentine et al, 2003). These skills in fact are not new for the pharmacist but their introduction, as systematized approach in everyday practice should correspond to the local circumstances. To match the context of the pharmaceutical care, defined by the APA as "Patient-centered, outcomes-oriented pharmacy practice that requires the pharmacist to work in concert with the patient to promote health, to prevent disease and to assess, monitor, initiate and modify medication use", is a real challenge for the management of diabetes, especially for Bulgaria.(American Pharmaceutical Association [APA], 2011). Despite the relatively small sample size, this study shows the role of education program for improvement of patient's outcomes. The results confirm the necessity of individual approach in the selection of therapeutic strategy for the women with GD. As the St. Vincent declaration assumed, the quality of life of people with diabetes has to be improved and to be promoted education of patients so to prevent diabetes complications. According to the St. Vincent declaration the aim of the treatment of GD is the achievement of child birth similar to the child birth by women without diabetes.(IDF, 2004) In this project are involved all healthcare givers, including the pharmacists in order to be achieved the goals. (Douglas et al., 2000; Dixon, 2002; Campbell et al., 1990; Mensing et al., 2002) The educational approach is a necessary step for better management of the disease in order to minimize the risk of maternal and fetal complications and the pharmacists are capable to perform it. The results obtained confirm the need for consistent patients' education, using variety of educational models, as an essential part of the diabetes care that will result in improvement of patient's quality of life. 


\section{Conclusion}

Gestational diabetes is a subject of endless debate, uncertainty and confusion. Although it is a alteration during pregnancy, the true prevalence of GD remains a matter of discussion. The prevalence of GD in the general population is varied from 1\% to $16 \%$ depending on both the country of origin and the nature of the indigenous population. The rate can vary due to differences in data collection methods, low response rates, non-random selection of the women, and lack of uniformity in the diagnostic criteria. More recently, the high rate of GD has been claimed to be an unrealistic estimation caused by universal screening, not carrying any specific benefit for pregnancy outcome.

GD is considered to be a state of prediabetes. The diagnosis of GD identifies women at high risk of diabetes after the pregnancy. Therefore, it is important for these women who may develop type 2 diabetes during their life to take preventive measures as well as to prevent pregnancy-related complications. It is well known that raised glucose levels in women with GD increase both morbidity and mortality among their offspring due mainly to an increased incidence of congenital abnormalities and excessive fetal growth in the third trimester. Women with a family history of diabetes had three times higher odds for GD than women without a family history of diabetes. With the prevalence of type 2 diabetes increasing across the world, and given that the prevalence of GD is thought to shadow that of type 2 diabetes, most populations will expect to see a rise in GD figures during the coming years. It is very important to establish clear policies to ensure that those at risk are reliably identified, appropriately treated during pregnancy and then equipped to make the necessary lifestyle changes to try and prevent them developing type 2 diabetes in later life.

\section{References}

ADA: American Diabetes Association. (2010). Standards of medical care in diabetes-2010. Diabetes Care, No 33, (Suppl 1):S11-61

ADA: American Diabetes Association. (2011). Standards of medical care in diabetes-2011. Diabetes Care, No 34(Suppl 1):S11-61

Ahlsson F, Lundgren M, Tuvemo T, Gustafsson J, Haglund B. (2010). Gestational diabetes and offspring body disproportion. Acta Pediatrica, No 99, pp.89-93

American College of Obstetricians and Gynaecologists Committee on Practice Bulletins - Obstetrics (2001) ACOG practice bulletin. Clinical management guidelines for obstetrician-gynecologists. No 30, September 2001 (replaces Technical Bulletin Number 200, December 1994). Gestational diabetes. Obstet Gynecol 98, pp.525538

American Diabetes Association.(2008) Clinical Practice Recommendations - Diagnosis and Classification of Diabetes Mellitus. Diabetes Care; No 31(Suppl. 1), S55-S60

American Pharmaceutical Association. (2011). Principles of practice for pharmaceutical care. Available from:

http://www.pharmacist.com/AM/Template.cfm?Section=Home2\&CONTENTID =2906\&TEMPLATE=/CM/HTMLDisplay.cfm) 
Bellamy L, Casas JP, Hingorani AD, Williams D. (2009). Type 2 diabetes mellitus after gestational diabetes: a systematic review and meta-analysis. Lancet. May Vol. 23; No. 373(9677), pp.1773-9.

Ben-Haroush A, Yogev Y, Hod M. (2004) Epidemiology of gestational diabetes mellitus and its association with Type 2 diabetes. Diabet Med. Feb;Vol. 21, No2, pp.103-13.

Bottalico JN.(2007). Recurrent gestational diabetes: risk factors, diagnosis, management, and implications. Semin Perinatol. Jun;Vol. 31, No3, pp. 176-84.

Campbell LV, Barth R, Gosper JK, Jupp JJ, Simons LA, Chisholm DJ. (1990) Impact of intensive educational approach to dietary change in NIDDM. Diabetes Care, No13, pp.841-7

Carolan M, Steele C, Margetts H. (2010) Knowledge of gestational diabetes among a multiethnic cohort in Australia. Midwifery, December Vol. 26, No.6, pp. 579-88.

Cetin M, Cetin A. (1997). Time-dependent gestational diabetes screening values. Int J Gynaecol Obstet. Mar; Vol. 56, No.3,pp. 257-61.

Chatzi L, Plana E, Pappas A, Alegkakis D, Karakosta P, Daraki V, Vassilaki M, Tsatsanis C, Kafatos A, Koutis A, Kogevinas M. (2009). The metabolic syndrome in early pregnancy and risk of gestational diabetes mellitus. Diabetes Metab. Vol. 35, No.6, pp.490-4.

Cho NH, Jang HC, Park HK, Cho YW. (2006). Waist circumference is the key risk factor for diabetes in Korean women with history of gestational diabetes. Diabetes Res Clin Pract, February, Vol. 71, No. 2, pp. 177-83.

Chu SY, Abe K, Hall LR, Kim SY, Njoroge T, Qin C. (2009). Gestational diabetes mellitus: all Asians are not alike. Prev Med. Aug-Sep, Vol.49, No.2-3, pp. 265-8.

Crowther C. et al (2005) Effect of treatment of gestational diabetes mellitus on pregnancy outcome, The New England Journal of Medicine, Vol. 352, No. 24, pp. 2477-2486

Davis TM. (2008).Ethnic diversity in type 2 diabetes. Diabet Med. August, 25 Suppl 2, pp. 52-6

Di Cianni G, Volpe L, Lencioni C, Miccoli R, Cuccuru I, Ghio A, Chatzianagnostou K, Bottone P, Teti G, Del Prato S, Benzi L. (2003). Prevalence and risk factors for gestational diabetes assessed by universal screening. Diabetes Res Clin Pract. November, Vol.62, No.2, pp.131-7.

Dixon N (2002) Pharmacists as a part of an extended diabetes team, Pharm J, No. 268, pp.469470

Douglas E, Hudson S, Bennie M, McGhee D, Dowers A, McShane C (2000) Pharmaceutical care needs in the primary care management of type 2 diabetes mellitus, Pharm J, No. 265, pp. 7114:R6, Available from

http://www.pharmj.com/Editorial/20000916/practiceresearch/r6.html Accessed 11 February 2004

Esakoff TF, Cheng YW, Caughey AB. (2005). Screening for gestational diabetes: different cut-offs for different ethnicities? Am J Obstet Gynecol. Sep;No. 193, pp.1040-4.

Fan ZT, Yang HX, Gao XL, Lintu H, Sun WJ. (2006). Pregnancy outcome in gestational diabetes. Int J Gynaecol Obstet. Jul. Vol. 94, No. 1, pp.12-6.

Ferrara A, Kahn HS, Quesenberry CP, Riley C, Hedderson MM. (2004). An increase in the incidence of gestational diabetes mellitus: Northern California, 1991-2000. Obstet Gynecol. Mar; Vol. 103, No.3, pp. :526-33. 
Ferrara A. (2007). Increasing prevalence of gestational diabetes mellitus: a public health perspective. Diabetes Care. Jul, Vol. 30 Suppl 2, pp.:S141-6.

Forsbach G, Cantú-Diaz C, Vázquez-Lara J, Villanueva-Cuellar MA, Alvarez y García C, Rodríguez-Ramírez E. (1997). Gestational diabetes mellitus and glucose intolerance in a Mexican population. Int J Gynaecol Obstet, Dec, Vol. 59, No. 3, pp.229-32.

Fraser R, Heller SR. (2007). Gestational diabetes: aetiology and management. Obst Gin Rep Med, Vol.17, No.12, pp.:345-348.

Georgiou H, Lappas M, Georgiou G, Marita A, Bryant V, Hiscock R, Permezel M, Khail Z, Rice G (2008) Screening for biomarkers predictive of gestational diabetes mellitus. Acta Diabetologica, No. 45, pp.157-165

Metzger BE, Lowe LP, Dyer AR, Trimble ER, Chaovarindr U, Coustan DR, Hadden DR, McCance DR, Hod M, McIntyre HD, Oats JJ, Persson B, Rogers MS, Sacks DA. (2008). Hyperglycemia and adverse pregnancy outcomes. NEngl J Med. No.358, pp.1991-2002

Harris SB, Caulfield LE, Sugamori ME, Whalen EA, Henning B. (1997). The epidemiology of diabetes in pregnant Native Canadians. A risk profile. Diabetes Care, September, Vol.20, No. 9, pp.1422-5.

Hillier TA, Pedula KL, Schmidt MM, Mullen JA, Charles MA, Pettitt DJ. (2007). Childhood obesity and metabolic imprinting: the ongoing effects of maternal hyperglycemia. Diabetes Care, September, Vol. 30, No. 9, pp.2287-92.

Hillier TA, Vesco KK, Pedula K,. Beil TL, Whitlock EP, Pettitt DJ. (2008). Screening for gestational diabetes mellitus: a systematic review for the US Preventive Services Task Force. Ann Intern Med, No 148, pp. 766-775.

Hossein-Nezhad A, Maghbooli Z, Vassigh AR, Larijani B. (2007). Prevalence of gestational diabetes mellitus and pregnancy outcomes in Iranian women. Taiwan J Obstet Gynecol, September, Vol. 46, No. 3, pp.:236-41.

Huda SS, Brodie LE, Sattar N. (2010). Obesity in pregnancy: prevalence and metabolic consequences. Semin Fetal Neonatal Med, Apr, Vol.15, No. 2, pp.70-6.

Hunsberger M, Rosenberg KD, Donatelle RJ. (2010). Racial/ethnic disparities in gestational diabetes mellitus: findings from a population-based survey. Womens Health Issues, September, Vol.20, No.5, pp.323-8.

Huxley R, James WP, Barzi F, Patel JV, Lear SA, Suriyawongpaisal P, Janus E, Caterson I, Zimmet P, Prabhakaran D, Reddy S, Woodward M. (2008). Obesity in Asia Collaboration. Ethnic comparisons of the cross-sectional relationships between measures of body size with diabetes and hypertension. Obes Rev, March, Vol. 9, Suppl 1, pp.53-61.

Hyer SL, Shehata HA. (2005). Gestational diabetes mellitus. Curr Obstet Gynecol, No. 15, pp.368-374

Metzger BE, Gabbe SG, Persson B, Buchanan TA, Catalano PA, Damm P, Dyer AR, Leiva A, Hod M, Kitzmiler JL, Lowe LP, McIntyre HD, Oats JJ, Omori Y, Schmidt MI. (2010). International association of diabetes and pregnancy study groups recommendations on the diagnosis and classification of hyperglycemia in pregnancy. Diabetes Care, No. 33, pp.676-682 
International Diabetes Federation, (2011). Diabetes Atlas, http://www.diabetesatlas.org/ International Diabetes Federation, (2004). St Vincent Declaration, Available from http://www.idf.org/e-atlas/home/index.cfm?node=71, Accessed 17 February 2004

Jang HC, Cho NH, Jung KB, Oh KS, Dooley SL, Metzger BE. (1995). Screening for gestational diabetes mellitus in Korea. Int J Gynaecol Obstet, Nov, Vol.51, No.2, pp.115-22

Jang HC, Yim CH, Han KO, Yoon HK, Han IK, Kim MY, Yang JH, Cho NH. (2003). Gestational diabetes mellitus in Korea: prevalence and prediction of glucose intolerance at early postpartum. Diabetes Res Clin Pract, Aug, Vol.61, No.2, pp.11724

Johnstone FD. (1999). Gestational diabetes. Curr Obstet Gynecol, No.9, pp.23-28

Joshy G, Simmons D. (2006). Epidemiology of diabetes in New Zealand: revisit to a changing landscape. N Z Med J, Jun Vol. 2. No.119(1235),U1999

Karcaaltincaba D, Kandemir O, Yalvac S, Güvendag-Guven S, Haberal A. (2009). Prevalence of gestational diabetes mellitus and gestational impaired glucose tolerance in pregnant women evaluated by National Diabetes Data Group and Carpenter and Coustan criteria. Int J Gynaecol Obstet, Sep, Vol.106, No.3, pp.2469.

Kim C, Berger DK, Chamany S. (2007). Recurrence of gestational diabetes mellitus: a systematic review. Diabetes Care, May, Vol.30, No. 5, pp.1314-9

Kimmerle R, Zass RP, Cupisti S, Somville T, Bender R, Pawlowski B, Berger M (1995) Pregnancies in women with diabetic nephropathy: long-term outcome for mother and child. Diabetologia No. 38, pp.227-235

Lawrence JM, Contreras R, Chen W, Sacks DA. (2008). Trends in the prevalence of preexisting diabetes and gestational diabetes mellitus among a racially/ethnically diverse population of pregnant women, 1999-2005. Diabetes Care, No.31, pp.899904.

Lopez-de-Andres A, Carrasco-Garrido P, Gil-de-Miguel A, Hernandez-Barrera V, JiménezGarcía R. (2011).Trends in deliveries in women with gestational diabetes in Spain, 2001-2008. Diabetes Res Clin Pract, Feb, Vol. 91, No.2, pp.27-9.

Madhavan A, Beena Kumari R, Sanal MG. (2008). A pilot study on the usefulness of body mass index and waist hip ratio as a predictive tool for gestational diabetes in Asian Indians. Gynecol Endocrinol. Dec, Vol.24, No.12, pp.701-7.

Mensing C, Boucher J, Cypress M, Weinger K, Mulcahy K, Barta P, et al. (2002) National standards for diabetes self-management education. Diabetes Care, No 25 (Suppl. 1):S140-7

Metzger B, Counstan DR (1998) Summary and recommendations of the fourth international workshop - conference on gestational diabetes mellitus. Diabetes Care, No. 21(Suppl 2):B161-B167

Metzger BE, Nelson L, Niznik C, Dooley SL. (2006) Update on gestational diabetes. Womens Health (Lond Engl). Mar;Vol. 2, No. 2, pp. 211-6

Ricart W, Lopez J, Mozas J, Pericot A, Sancho MA, González N, Balsells M, Luna R, Cortázar A, Navarro P, Ramírez O, Flández B, Pallardo LF, Hernández A, Ampudia J, 
Fernández-Real JM, Corcoy R; (2005). Spanish Group for the Study of the Impact of Carpenter and Coustan GD thresholds. Potential impact of American Diabetes Association (2000) criteria for diagnosis of gestational diabetes mellitus in Spain. Diabetologia, Vol. 48, No.6, pp.1135-41

Rosenberg TJ, Garbers S, Chavkin W, Chiasson MA. (2003). Prepregnancy weight and adverse perinatal outcomes in an ethnically diverse population. Obstet Gynecol. Nov, No.102, pp.1022-7

Sahu L, satyakata R, Rani R. (2009). Comparison of the American Dia betes Association and World health Organisation criteria for gestational diabetes mellitus and the outcomes of pregnancy. Obstet Med, No.2, pp.149-153

Satman I, Yilmaz T, Sengul A, Salman S, Salman F, Uygur S, Bastar I, Tütüncü Y, Sargin M, Dinççag N, Karsidag K, Kalaça S, Ozcan C, King H. (2002).Population-based study of diabetes and risk characteristics in Turkey: results of the Turkish diabetes epidemiology study (TURDEP). Diabetes Care, Vol.25, No.9, pp.1551-6

Savitz DA, Janevic TM, Engel SM, Kaufman JS, Herring AH. (2008). Ethnicity and gestational diabetes in New York City, 1995-2003. BJOG, Jul, Vol.115, No.8, pp.96978

Scholl TO, Chen X, Gaughan C, Smith WK. (2002). Influence of maternal glucose level on ethnic differences in birth weight and pregnancy outcome. Am J Epidemiol, Sep 15, Vol.156, No.6, pp.498-506

Shai I, Jiang R, Manson JE, Stampfer MJ, Willett WC, Colditz GA, Hu FB. (2006). Ethnicity, obesity, and risk of type 2 diabetes in women: a 20-year follow-up study. Diabetes Care,Vol.29, No.7, pp.1585-90

Sinha B, Brydon P, Taylor RS, Hollins A, Munro A, Jenkins D, Dunne F. (2003). Maternal ante-natal parameters as predictors of persistent postnatal glucose intolerance: a comparative study between Afro-Caribbeans, Asians and Caucasians. Diabet Med, Vol. 20, No.5, pp.382-6

The DECODA Study Group. Age- and sex-specific prevalence of diabetes and impaired glucose regulation in 11 Asian cohorts. Diabetes Care. 2003;26:1770-1780

The Diabetes Control and Complications Trial Research Group. (1996). Pregnancy outcomes in the Diabetes Control and Complications Trial (DCCT). Am J Obstet Gynecol, No.174, pp.1343-1353

Todorova K., Palaveev O, Petkova V., Stefanova M., Dimitrova Zl. (2007) A pharmcoeconomical model for choice of a treatment for pregnant women with gestational diabetes. Acta Diabetologica, Vol. 44, No.3, pp.144-148,

Valentine V, Kulkarni K, Hinnen D. (2003). Evolving roles: from diabetes educators to advanced diabetes managers. Diabetes Spectrum, Vol. 16,No. 1, pp.27-31

Villamor E, Cnattingius S. (2006). Interpregnancy weight change and risk of adverse pregnancy outcomes: a population-based study. Lancet, Sep 30;Vol. 368, No. 9542, pp.1164-70.

Wrongdiagnosis.com, Statistics by Country for Gestational diabetes http://www.wrongdiagnosis.com/g/gestdiab/stats-country.htm?ktrack=kcplink (2011) 
Xiong X, Saunders LD, Wang FL, Demianczuk NN. (2001).Gestational diabetes mellitus: prevalence, risk factors, maternal and infant outcomes. Int J Gynaecol Obstet, Dec;Vol.75, No.3, pp.221-8. 


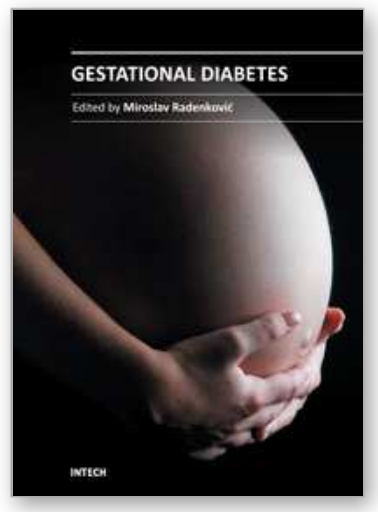

\author{
Gestational Diabetes \\ Edited by Prof. Miroslav Radenkovic
}

ISBN 978-953-307-581-5

Hard cover, 382 pages

Publisher InTech

Published online 02, November, 2011

Published in print edition November, 2011

Gestational diabetes mellitus is defined as hyperglycemia with onset or first recognition during pregnancy. The incidence of gestational diabetes is still increasing and this pathological condition has strong association with adverse pregnancy outcomes. Since gestational diabetes can have long-term pathological consequences for both mother and the child, it is important that it is promptly recognized and adequately managed. Treatment of gestational diabetes is aimed to maintain euglycemia and it should involve regular glucose monitoring, dietary modifications, life style changes, appropriate physical activity, and when necessary, pharmacotherapy.

Adequate glycemic control throughout the pregnancy can notably reduce the occurrence of specific adverse perinatal and maternal outcomes. In a long-term prospect, in order to prevent development of diabetes later in life, as well to avoid associated complications, an adequate education on lifestyle modifications should start in pregnancy and continue postpartum.

\title{
How to reference
}

In order to correctly reference this scholarly work, feel free to copy and paste the following:

Valentina Petkova and Irina Nikolova (2011). Prevalence and Risk Factors for the Development of GD in Some Eastern European Countries - Tendencies and Pharmacoeconomical Assessment for the Choice of Treatment, Gestational Diabetes, Prof. Miroslav Radenkovic (Ed.), ISBN: 978-953-307-581-5, InTech, Available from: http://www.intechopen.com/books/gestational-diabetes/prevalence-and-risk-factors-for-thedevelopment-of-gd-in-some-eastern-european-countries-tendencies-

\section{INTECH}

open science | open minds

\section{InTech Europe}

University Campus STeP Ri

Slavka Krautzeka 83/A

51000 Rijeka, Croatia

Phone: +385 (51) 770447

Fax: +385 (51) 686166

www.intechopen.com

\section{InTech China}

Unit 405, Office Block, Hotel Equatorial Shanghai

No.65, Yan An Road (West), Shanghai, 200040, China

中国上海市延安西路65号上海国际贵都大饭店办公楼405单元

Phone: +86-21-62489820

Fax: $+86-21-62489821$ 
(C) 2011 The Author(s). Licensee IntechOpen. This is an open access article distributed under the terms of the Creative Commons Attribution 3.0 License, which permits unrestricted use, distribution, and reproduction in any medium, provided the original work is properly cited. 